\title{
Pesquisa-ação na engenharia de produção: proposta de estruturação para sua condução
}

\author{
Carlos Henrique Pereira Mello ${ }^{\mathrm{a} *}$, João Batista Turrioni ${ }^{\mathrm{b}}$, \\ Amanda Fernandes Xavierc, Danielle Fernandes Campos ${ }^{\mathrm{d}}$ \\ a*carlos.mello@unifei.edu.br, UNIFEl, Brasil \\ b4058@unifei.edu.br, UNIFEl, Brasil \\ 'mandinhaje@yahoo.com.br, UNIFEl, Brasil \\ ddfc.unifei.2008@gmail.com, UNIFEl, Brasil
}

\begin{abstract}
Resumo
A pesquisa-ação é um método de pesquisa qualitativa que cada vez mais se destaca como estratégia de pesquisa adotada em engenharia de produção. Contudo, esse método sofre com preconceitos a respeito do seu mérito científico, bem como com uma indefinição de como sua condução pode ser validada. Visando minimizar essas lacunas da literatura, a partir de uma pesquisa de cunho conceitual-teórico, o presente trabalho visa propor um processo para o planejamento e condução de pesquisas na engenharia da produção por meio da pesquisa-ação. Consideram-se como contribuições científicas do presente trabalho a discussão acerca das formas de iniciação e das etapas de validação das pesquisas que empregam o método da pesquisa-ação. Conclui-se que, dentro do paradigma científico do realismo, os critérios mais adequados para a validação da pesquisa-ação são a adequação ontológica, a validade contingente, a percepção múltipla dos participantes, a fidedignidade metodológica, a generalização analítica e a validade do construto.
\end{abstract}

Palavras-chave

Engenharia de produção. Pesquisa-ação. Metodologia de pesquisa.

\section{Introdução}

A pesquisa qualitativa apresentou um considerável crescimento a partir da década de 1970 , baseada em métodos das ciências sociais (BRYMAN, 1989). Na pesquisa qualitativa, diferentemente da quantitativa, o pesquisador busca compreender os fenômenos observando-os, interpretando-os e descrevendo-os.

Dentre os métodos empregados na pesquisa qualitativa destacam-se o estudo de caso e a pesquisaação. Apesar do estudo de caso ser o método mais empregado nos trabalhos apresentados no Encontro Nacional de Engenharia de Produção (BERTO; NAKANO, 2000), Craighead e Meredith (2008) afirmam que a pesquisa-ação é um dos métodos qualitativos emergentes, podendo ser empregada para que o pesquisador aprofunde seus conhecimentos acerca de um fenômeno e estabeleça questões de pesquisa mais pertinentes.
Entretanto, a pesquisa-ação sofre alguns preconceitos quanto a ser considerada um método científico e há até mesmo uma confusão desta com atividades de consultoria, tal como destacado por Westbrook (1995) e Coughlan e Coghlan (2002). Esse método atenderia a qual paradigma científico? Outra questão relevante sobre esse método é em relação à sua forma de validação. Diversos autores (CHECKLAND; HOLWELL, 1998; WINTER, 2002; McINNES; HIBBERT; BEECH, 2007) comentam sobre essa questão sem chegar a uma definição sobre ela. Que critérios poderiam ser adotados para validar uma pesquisa científica que adote esse método?

Outra questão interessante que pode ser levantada sobre esse método é em relação ao seu processo de iniciação. A maioria dos métodos começa com a leitura da bibliografia pertinente para a 
identificação de lacunas na literatura, que motivariam o desenvolvimento de questões de pesquisa e a realização da pesquisa para respondê-las. Contudo, em boa parte dos programas de pós-graduação das universidades brasileiras, alguns pesquisadores que trabalham em empresas já trazem consigo alguns problemas que necessitam de solução. Daí, fazem o processo inverso, ou seja, partem dos problemas e buscam na literatura as possíveis soluções. Daí a pergunta: como iniciar um processo de pesquisa por meio da pesquisa-ação? Entretanto, essa inversão exige do pesquisador um conhecimento prévio sobre o tema. Isso é uma limitação para o uso da pesquisa-ação por pesquisadores iniciantes que, em algumas situações, podem confundir a pesquisa-ação com um relato de condução de um projeto de consultoria, não levando em conta os devidos cuidados de cunho científico.

Para responder principalmente às questões citadas, o objetivo deste trabalho é propor um processo para a condução de pesquisas por meio da pesquisa-ação analisando formas adequadas para o desenvolvimento de sua iniciação, discutindo sobre o paradigma científico mais adequado para esse método de pesquisa e definindo critérios para sua validação.

A abordagem metodológica da presente pesquisa é de cunho teórico-conceitual tal como definida por Filippini (1997), baseada na análise da literatura, visando levantar uma série de pontos relevantes para o planejamento e condução da pesquisa-ação como método de pesquisa na engenharia de produção.

\section{Origens, definições e características da pesquisa-ação}

Segundo Carr (2006), a história da pesquisa-ação pode ser dividida em dois estágios. 0 primeiro cobre 0 período entre 1920 e 1950. Durante este intervalo, Kurt Lewin publicou o que diversos pesquisadores (SUSMAN; EVERED, 1978; WESTBROOK, 1995; BASKERVILLE; PRIES-HEJE, 1999; COUGHLAN; COGHLAN, 2002) consideram o primeiro trabalho sobre este método de pesquisa, no qual pela primeira vez se utiliza o termo pesquisa-ação no meio científico.

0 segundo estágio da evolução histórica da pesquisa-ação se deu por volta da década de 1970, com sua aplicação no contexto da pesquisa na área educacional no Reino Unido. Pode-se dizer que se tratava de uma versão aperfeiçoada daquela proposta por Lewin, por rejeitar o método de pesquisa positivista em favor de um método mais interpretativo, com foco nas perspectivas dos participantes e dos atores sociais (CARR, 2006).

Para Bryman (1989), a pesquisa-ação é uma abordagem da pesquisa social aplicada na qual o pesquisador e o cliente colaboram no desenvolvimento de um diagnóstico e para a solução de um problema, por meio da qual as descobertas resultantes irão contribuir para a base de conhecimento em um domínio empírico particular.

Na pesquisa-ação, o termo pesquisa se refere à produção do conhecimento e o termo ação, à uma modificação intencional de uma dada realidade. A pesquisa-ação é a produção de conhecimento guiada pela prática, com a modificação de uma dada realidade ocorrendo como parte do processo de pesquisa. Neste método de pesquisa, o conhecimento é produzido e a realidade é modificada simultaneamente, cada um ocorrendo devido ao outro (OQUIST, 1978).

Thiollent (2007) ressalta que para uma pesquisa ser qualificada como pesquisa-ação é vital a implantação de uma ação por parte das pessoas ou grupos implicados no problema sob observação. Além disso, é necessário que a ação seja não-trivial, o que quer dizer uma ação problemática que mereça investigação, sob o ponto de vista científico, para ser elaborada e conduzida. Na pesquisa-ação os pesquisadores desempenham um papel ativo no equacionamento dos problemas encontrados, no acompanhamento e na avaliação das ações desencadeadas em função dos problemas.

A configuração da pesquisa-ação depende dos seus objetivos e do contexto no qual é aplicada. Quanto a seus objetivos, a pesquisa-ação é organizada para realizar os objetivos técnicos de um ator social que dispõe de suficiente autonomia para encomendar e controlar a pesquisa. Os pesquisadores assumem os objetivos definidos e orientam a investigação em função dos meios disponíveis. Quanto ao contexto, a pesquisa-ação é realizada dentro de uma organização (empresa ou instituição) na qual existe hierarquia ou grupos cujos relacionamentos apresentam problemas (THIOLLENT, 2007). Portanto, a pesquisa-ação é uma estratégia de pesquisa na engenharia de produção que visa produzir conhecimento e resolver um problema prático. A relação entre essas duas preocupações é variável, porém um equilíbrio entre as duas seria desejável. Thiollent (2007) define esses dois objetivos como:

a) Objetivo técnico: contribuir para o melhor equacionamento possível do problema considerado central na pesquisa, com levantamento de soluções e proposta de ações correspondentes às soluções para auxiliar o agente na sua atividade transformadora da situação;

b) Objetivo científico: conseguir informações que seriam de difícil obtenção por meio de outros procedimentos, de forma a aumentar a base de conhecimento de determinadas situações. 
Coghlan e Brannick (2008) consideram que a pesquisa-ação é apropriada quando a questão da pesquisa relaciona-se com descrever o desdobramento de uma série de ações ao longo do tempo em um dado grupo, comunidade ou organização; para explicar como e porque a ação de um membro de um grupo pode mudar ou melhorar o trabalho de alguns aspectos do sistema; e para entender o processo de mudança ou de melhoria e aprender com ele.

\section{Cientificidade da pesquisa-ação}

Não é de hoje que o mérito científico da pesquisaação é questionado e julgado (SUSMAN; EVERED, 1978; OQUIST, 1978). Uma das principais críticas que se faz ao método da pesquisa-ação é que ela se assemelha a um projeto de consultoria. Essa crítica é comentada por autores como Westbrook (1995) e Coughlan e Coghlan (2002), que destacam as seguintes diferenças entre uma e outra:

- As consultorias não tem como meta desenvolver ou refinar uma teoria (o que se espera do uso de um método de pesquisa), mas simplesmente relatar a realização de um projeto empírico que, mesmo que apresente alguma inovação, pouco tem a acrescentar a uma base de conhecimento;

- Os relatos de trabalhos de consultoria se importam apenas com os casos de sucesso, não explorando os obstáculos encontrados pelo caminho, que podem ser úteis para outros interessados; ao utilizar a pesquisa-ação, o pesquisador relata também os obstáculos encontrados e eles podem contribuir nos resultados da pesquisa;

- A consultoria é frequentemente linear (contratação, análise, ação e encerramento); em contraste, a pesquisa-ação é cíclica (coleta de dados, realimentação, análise, planejamento das ações, implementação das ações e avaliação), conduzindo para uma próxima etapa de coleta de dados e assim sucessivamente;

- A consultoria não se preocupa com a posição epistemológica a ser adotada para a realização e relato de suas ações, ao contrário do que se espera de um método de pesquisa como a pesquisa-ação.

Sendo assim, considera-se que um trabalho de consultoria, a princípio, não pode ser considerado cientificamente como uma pesquisa-ação ou servir de base para ela. Para isso acontecer é necessário que o trabalho de consultoria comece a ser planejado desde o seu início como um projeto científico, considerando todas as fases descritas no presente trabalho. De outro modo ele terá sua confiabilidade e validade contestadas pela comunidade científica.

Contudo, existem diversas posições epistemológicas ou paradigmas de pesquisa científica, ou seja, estruturas conceituais gerais, sob as quais os pesquisadores trabalham, que são formas de observar o mundo através de pressupostos compartilhados por uma comunidade de cientistas que investigam esse mundo (DESHPANDE, 1983).

Guba e Lincoln (1994) resumem os paradigmas científicos em quatro categorias: positivismo, realismo, teoria crítica e construtivismo. Cada um desses paradigmas são explicados a partir de três elementos: ontologia, epistemologia e metodologia. Healy e Perry (2000) definem ontologia como a natureza da realidade, epistemologia como a relação entre a realidade e o pesquisador e metodologia como o procedimento técnico empregado pelo pesquisador para investigar a realidade.

Healy e Perry (2000) afirmam que não existe pesquisa científica livre desses paradigmas, e que não há fundamento objetivo que determine a escolha e utilização de um deles. Tudo que o pesquisador pode fazer é trabalhar dentro de um paradigma consistente com os seus pressupostos científicos, que geralmente não podem ser testados em nenhum fundamento empírico ou lógico. Daí vem um questionamento: qual desses paradigmas é mais consistente com o caráter científico da pesquisa-ação?

Thompson e Perry (2004) compararam esses quatro paradigmas. Um resumo desta comparação é apresentado no Quadro 1.

Segundo Thompson e Perry (2004), o realismo é o paradigma que mais se adéqua à pesquisa-ação. A ontologia do realismo considera que existe apenas um mundo "real" a ser descoberto, o qual é externo aos pensamentos do pesquisador. Contudo, esse mundo é apenas imperfeita e probabilisticamente compreensivel, ao contrário do paradigma do positivismo. Ou seja, as descobertas (ou evidências) observadas são meros afloramentos de uma realidade mais profunda, observada e observável. Dessa forma, o realismo não busca estabelecer relações causais diretas, como faz o positivismo, contudo, ele reconhece que um conjunto de respostas a respeito de tendências causais no mundo externo social pode ser desenvolvido a partir da pesquisa. Assim, os dados (evidências) podem ser triangulados na busca por refletir um quadro mais preciso da realidade externa e entrevistas com especialistas nos campos de conhecimento da pesquisa podem contribuir para fornecer informações adicionais.

\section{Estruturação da pesquisa-ação}

$\mathrm{Na}$ pesquisa-ação, o pesquisador, utilizando a observação participante, interfere no objeto de estudo de forma cooperativa com os participantes da ação para resolver um problema e contribuir para a base do conhecimento. 
Quadro 1. Quatro categorias de paradigmas científicos e seus elementos.

\begin{tabular}{|c|c|c|c|c|}
\hline Elemento & Positivismo & Teoria crítica & Construtivismo & Realismo \\
\hline Ontologia & $\begin{array}{l}\text { Realidade é real e } \\
\text { compreensível }\end{array}$ & $\begin{array}{l}\text { Realidade "virtual" formada por } \\
\text { valores sociais, econômicos, étnicos, } \\
\text { políticos, culturais e de gênero }\end{array}$ & $\begin{array}{l}\text { Realidades em } \\
\text { locais múltiplos } \\
\text { e construídas } \\
\text { especificamente }\end{array}$ & $\begin{array}{c}\text { Realidade é "real”, mas apenas } \\
\text { imperfeitamente e probabilisticamente } \\
\text { compreensivel }\end{array}$ \\
\hline Epistemologia & Descobertas verdadeiras & Descobertas mediadas pelos valores & Descobertas criadas & Descobertas provavelmente verdadeiras \\
\hline $\begin{array}{l}\text { Metodologias } \\
\text { mais comuns }\end{array}$ & $\begin{array}{c}\text { Experimentos, } \\
\text { surveys, verificação } \\
\text { de hipóteses, } \\
\text { principalmente os } \\
\text { métodos quantitativos. }\end{array}$ & $\begin{array}{l}\text { Pesquisador como um } \\
\text { "transformador intelectual" que } \\
\text { altera o mundo social no qual os } \\
\text { participantes vivem. }\end{array}$ & $\begin{array}{l}\text { Pesquisador é } \\
\text { um “participante } \\
\text { passional” no } \\
\text { mundo que está } \\
\text { sendo investigado. }\end{array}$ & $\begin{array}{l}\text { Estudos de caso/ entrevistas } \\
\text { convergentes: triangulação, } \\
\text { interpretação de questões da } \\
\text { investigação por métodos quantitativos } \\
\text { e qualitativos, tal como a modelagem } \\
\text { de equações estruturais. }\end{array}$ \\
\hline
\end{tabular}

Fonte: Thompson e Perry (2004) e Healy e Perry (2000).

A proposta de conteúdo e sequência para a condução da pesquisa-ação, construída pelos autores com base nos trabalhos de Westbrook (1995), Coughlan e Coghlan (2002) e Thiollent (2007), pode ser vista na Figura 1. Cada ciclo do processo da pesquisa-ação acontece em cinco fases: planejar; coletar dados; analisar dados e planejar ações; implementar ações; avaliar resultados e gerar relatório. Cada uma dessas fases é discutida a seguir.

Todas essas fases, etapas e atividades, detalhadas na Figura 2, e mais uma outra, denominada de ciclo de melhoria e aprendizagem (planejar, implementar, observar/avaliar, refletir/agir), formam a estrutura para pesquisa-ação proposta por este trabalho. As fases são apresentadas em uma única sequência, sendo que as implicações da necessidade de alteração dessa sequência, em virtude da forma de iniciação, são comentadas em cada tópico específico nesta seção.

\subsection{Planejar a pesquisa-ação}

Esta fase é composta por três etapas: definição da estrutura conceitual-teórica, seleção da unidade de análise e técnicas de coleta de dados e definição do contexto e propósito da pesquisa. Dependendo da forma de iniciação, essas três etapas podem ser conduzidas em ordens diferentes. A Figura 3 apresenta a organização da fase de planejamento da pesquisaação, conforme o seu tipo de iniciação.

\subsubsection{Iniciação da pesquisa}

Uma pesquisa que adota como método a pesquisaação pode-se iniciar com o pesquisador identificando um problema na literatura e depois buscando um objeto de estudo onde esse problema possa ser resolvido cientificamente. $\mathrm{Ou}$, ainda, com uma organização definindo um problema e o pesquisador participando das propostas para sua solução por meio do emprego de um método de pesquisa (neste caso, a pesquisa-ação).
Conforme Avison, Baskerville e Myers (2001), na primeira possibilidade trata-se da iniciação dirigida pelo pesquisador, na qual o pesquisador já realizou uma fundamentação teórica inicial, identificou algumas lacunas e agora procura cenários que possam ser característicos desses problemas e que mereçam ser resolvidos. Nesta situação, será necessário escolher uma unidade de análise para a realização da pesquisa.

Na segunda possibilidade, trata-se da iniciação dirigida pelo problema, na qual os integrantes de uma dada organização podem ter se defrontado com um problema aparentemente insuperável e estão à procura de um especialista teórico (pesquisador) para resolvê-lo. Nesta situação, o pesquisador pode ter que desenvolver uma fundamentação teórica oportuna, empreendendo uma série de projetos de pesquisa com vasto arcabouço teórico. 0 pesquisador busca aprender com estas experiências e esboçar conclusões que o auxiliem a avançar no desenvolvimento de uma teoria (AVISON; BASKERVILLE; MYERS, 2001). Não é raro este tipo de iniciação acontecer em pesquisas de programas de pós-graduação de algumas universidades brasileiras, quando um mestrando oriundo de uma empresa do setor privado ou público procura estabelecer como problema de pesquisa uma dificuldade identificada no seu ambiente de trabalho que mereça uma proposta de solução adequada. Em geral, essa solução precisa contribuir para a melhoria das práticas organizacionais e para a base de conhecimento.

Nessa etapa de iniciação é também importante definir a autoridade para o projeto de pesquisa-ação (AVISON; BASKERVILLE; MYERS, 2001). A organização pode permitir que a autoridade final para uma ação na unidade de análise seja exercida por um pesquisador externo. Nesse caso, toda a equipe de pesquisadores (formada por acadêmicos externos e profissionais da organização estudada) pode atuar de forma consultiva, ou seja, recomendando aos tomadores de decisão as ações a serem implementadas (e seus resultados).

As três próximas etapas são apresentadas na sequência proposta para a iniciação dirigida pelo 


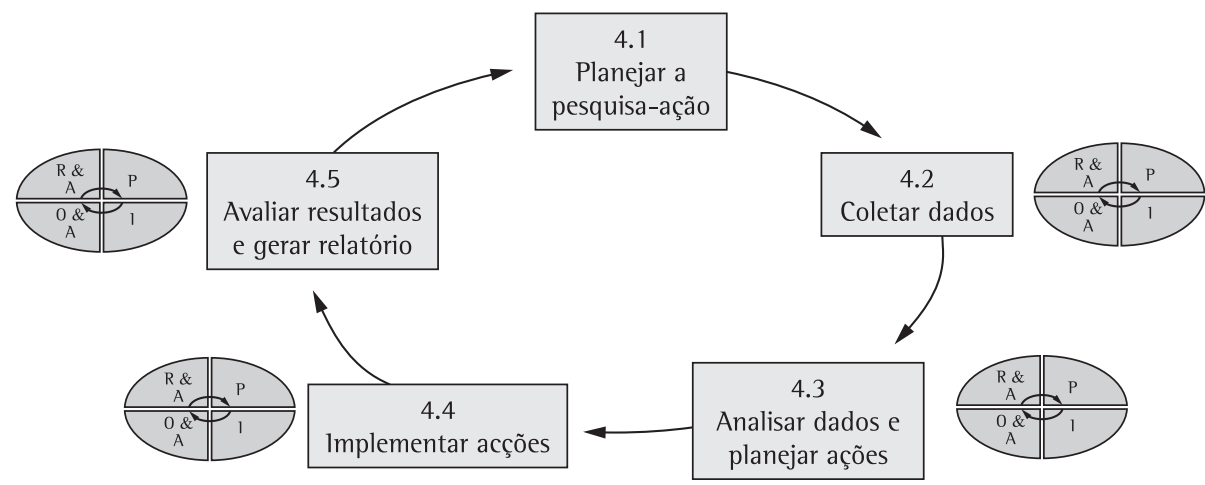

Figura 1. Estruturação para condução da pesquisa-ação. Fonte: adaptado de Westbrook (1995), Coughlan e Coghlan (2002) e Thiollent (2007).

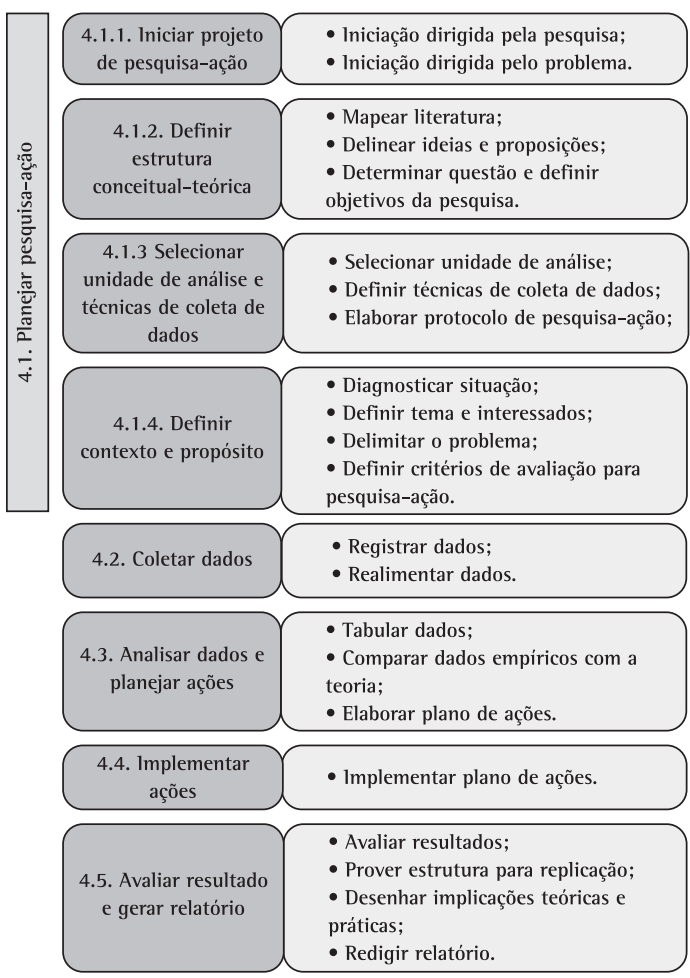

Figura 2. Detalhamento das fases, etapas e atividades da estrutura proposta para pesquisa-ação quando iniciadas pelo pesquisador.

pesquisador. Contudo, as implicações das adequações necessárias para a iniciação dirigida pelo problema são comentadas nos tópicos pertinentes.

\subsubsection{Definir a estrutura conceitual-teórica}

A fundamentação teórica é uma visão crítica da pesquisa existente que é significante para o trabalho que está sendo desenvolvido, sendo importante o mapeamento da literatura existente e ao alcance do pesquisador. Creswell (2007, p. 55) define o mapa da literatura como "[...] um sumário visual da pesquisa conduzida por outras pessoas, sendo geralmente representado por uma figura”. Em sua obra, esse autor descreve como organizar um mapa de literatura e discute algumas diretrizes gerais para a sua elaboração.

Rowley e Slack (2004) afirmam que a fundamentação teórica identifica e organiza os conceitos encontrados em trabalhos relevantes. 0 objetivo da mesma é captar o estado da arte de um campo do conhecimento. A partir dessa revisão de trabalhos antigos (clássicos) e recentes, torna-se possível identificar áreas nas quais uma pesquisa mais profunda poderia ser benéfica. É necessário estudar a bibliografia pertinente de modo sistemático e reconstrutivo para elaborar uma base teórica de caráter explicativo.

Além disso, a fundamentação teórica auxilia também a olhar criticamente a realidade sob a forma dos trabalhos publicados. Essa análise crítica geralmente requer que o pesquisador primeiro desconstrua um tema em seus elementos básicos. A crítica identifica os pontos fortes e as contribuições chave da literatura, assim como as deficiências, omissões, inexatidões e outros aspectos problemáticos da literatura. Ela também identifica o conhecimento que deve ser criado ou aperfeiçoado à luz dos desenvolvimentos recentes sobre o tema (TORRAC0, 2005).

Na pesquisa-ação, a fundamentação teórica identifica as lacunas onde podem existir problemas a serem solucionados, preferencialmente em comunhão com um contexto organizacional que promova a pesquisa participativa entre pesquisadores e profissionais. Esses problemas, após analisados, podem gerar uma questão de pesquisa a partir da qual são definidos os objetivos (geral e específicos) de um projeto de pesquisa. 


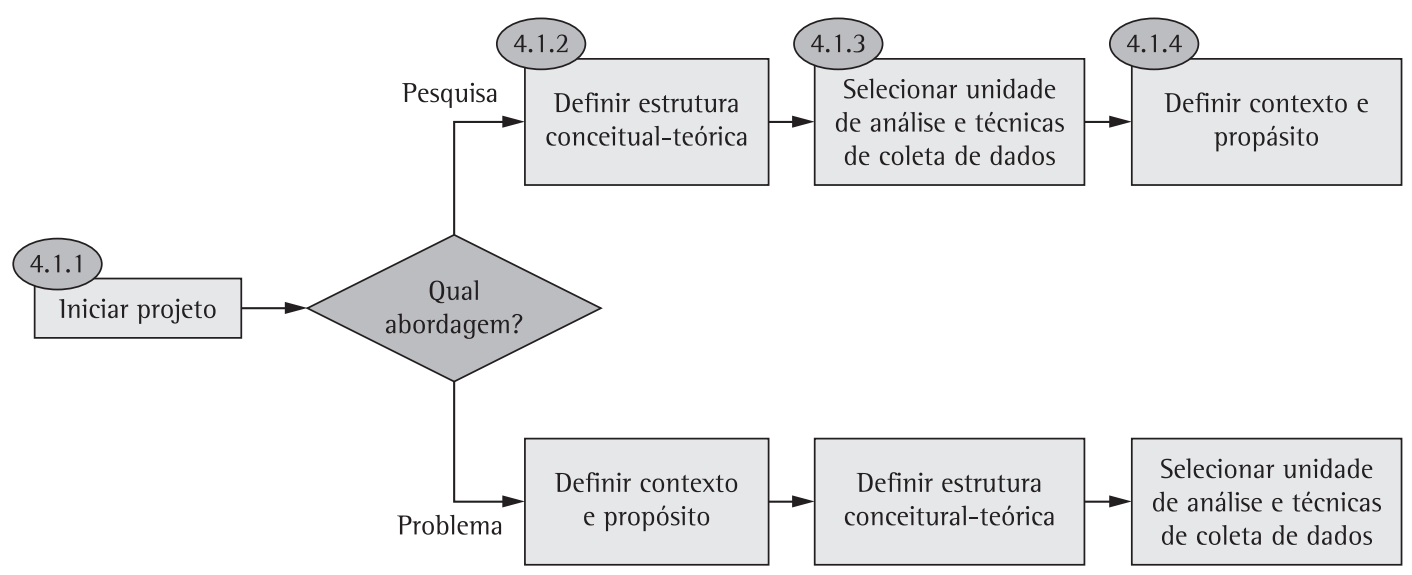

Figura 3. Estrutura da fase de planejamento da pesquisa-ação.

Na abordagem dirigida pelo problema, a definição da estrutura conceitual-teórica é realizada após o diagnóstico e definição do problema organizacional a ser solucionado, uma vez que, nesta abordagem, os profissionais de uma dada organização é que estão em busca de um pesquisador para solucionar esse problema cientificamente. Nesse caso, o pesquisador realiza a fundamentação teórica para contextualizar e fundamentar os problemas identificados, podendo haver um redirecionamento ou reformulação desse problema para sua adaptação ao estado da arte do conhecimento sobre o tema ou a uma lacuna identificada. A questão de pesquisa e seus objetivos são definidos com o intuito de propor recomendações para solucionar o problema e contribuir para a base de conhecimento.

\subsubsection{Selecionar unidade de análise e técnicas de coleta de dados}

$\mathrm{Na}$ abordagem da pesquisa-ação com iniciação motivada pelo problema, onde a pesquisa nasce dentro de uma organização, a definição da unidade de análise já foi realizada. Contudo, na abordagem com iniciação motivada pela pesquisa, esta etapa de planejamento começa pela seleção da unidade de análise.

Yin (2005) considera que a definição da unidade de análise está relacionada à maneira como as questões iniciais da pesquisa foram definidas. $\mathrm{Na}$ pesquisa-ação, os problemas identificados pela fundamentação teórica também devem ser levados em conta para a seleção da unidade de análise. Para nortear e justificar a escolha da unidade de análise mais adequada para a condução da pesquisa o mais correto seria definir critérios com base na questão da pesquisa e nos problemas a serem solucionados.
Yin (2005) sugere discutir esses critérios com outros pesquisadores, de forma a evitar a seleção incorreta da unidade de análise.

0 planejamento da pesquisa-ação envolve a definição das técnicas a serem empregadas na coleta de dados. A combinação e uso de diferentes técnicas favorece a validação da pesquisa. Woodside e Wilson (2003) afirmam que a triangulação frequentemente inclui: observação participante do pesquisador no ambiente da pesquisa, sondagens através de questionamento dos participantes quanto a explicações e interpretações dos dados operacionais e análise de documentos escritos e do locais integrantes do ambiente da unidade de análise estudada.

Segundo Thiollent (2007), as principais técnicas utilizadas são a entrevista coletiva nos locais de trabalho e a entrevista individual aplicada de modo aprofundado. Ao lado dessas técnicas também são utilizados questionários convencionais que são aplicáveis em maior escala. No que diz respeito à informação já existente, diversas técnicas documentais permitem resgatar e analisar o conteúdo de arquivos internos da organização estudada.

Entretanto, na pesquisa-ação a técnica mais empregada é a observação participante. Segundo Marconi e Lakatos (2006), consiste na participação ou interação real do pesquisador com a comunidade ou grupo. 0 pesquisador se incorpora ao grupo e exerce influência sobre ele. 0 objetivo principal seria ganhar a confiança do grupo e fazer os indivíduos compreenderem a importância da investigação, sem ocultar o seu objetivo ou missão.

Apesar da pesquisa-ação ser um método com características diferentes do estudo de caso, onde o pesquisador trabalha inserido no grupo de pesquisa e com maior liberdade de atuação, a elaboração de um protocolo de pesquisa é recomendável para a 
melhoria da confiabilidade dessa pesquisa. 0 Quadro 2 apresenta as seções típicas para a elaboração de um protocolo de pesquisa-ação.

Como Westbrook (1995) afirma que a pesquisaação é uma variação do estudo de caso, considera-se que as seções típicas para o protocolo apresentadas no Quadro 3 sejam adequadas para a pesquisa-ação.

Os trabalhos de Leonel (2007) e Chimendes (2007) apresentam exemplos de roteiros de entrevistas como parte de um protocolo de pesquisa para orientar o pesquisador na coleta de dados. French (2009) apresenta um roteiro para a elaboração de protocolos para a pesquisa-ação.

\subsubsection{Definir contexto e propósito}

Para Coughlan e Coghlan (2002), essa etapa é dirigida por duas questões relacionadas com a racionalidade para a ação e para a pesquisa, como mostra o Quadro 3.

Quadro 2. Seções típicas de um protocolo de pesquisa para pesquisa-ação.

\begin{tabular}{|c|c|}
\hline Seção & Conteúdo \\
\hline 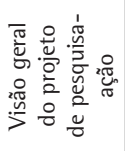 & $\begin{array}{l}\text { - Objetivos e patrocínios do projeto; } \\
\text { - Questões de pesquisa; } \\
\text { - Problema prático a ser solucionado; } \\
\text { - Contribuição científica para a base de conhecimento; } \\
\text { - Leituras importantes sobre o tópico investigado. }\end{array}$ \\
\hline 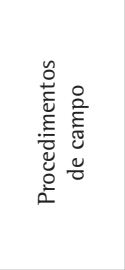 & $\begin{array}{l}\text { - Definição da unidade de análise; } \\
\text { - Definição do grupo de pesquisa (pesquisadores e } \\
\text { participantes da unidade de análise); } \\
\text { - Definir autoridade para pesquisa-ação; } \\
\text { - Estabelecer uma agenda adequada das ações para } \\
\text { coleta de dados; } \\
\text { - Definir ciclos da pesquisa-ação (ciclo de melhoria e } \\
\text { - Fprendizagem); } \\
\text { - Fontes gerais de informações. }\end{array}$ \\
\hline 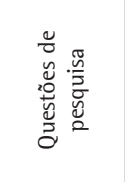 & $\begin{array}{l}\text { - Questões específicas para o pesquisador para coleta } \\
\text { de dados; } \\
\text { - Lista de fontes de evidências prováveis após cada } \\
\text { - Puestão; } \\
\text { - Planilha para disposição de dados; } \\
\text { - Fontes potenciais de informações para cada questão. }\end{array}$ \\
\hline 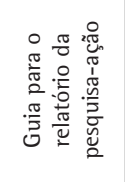 & $\begin{array}{l}\text { - Resumo; } \\
\text { - Formato de narrativa; } \\
\text { - Indicação da quantidade de documentos utilizados } \\
\text { - Eo relatório; } \\
\text { - Especificação de informações bibliográficas; } \\
\text { - Especificação de outras documentações. }\end{array}$ \\
\hline
\end{tabular}

Fonte: Adaptado de Yin (2005).
Thiollent (2007) considera esta etapa exploratória, consistindo em descobrir o campo de pesquisa, os interessados e suas expectativas e em estabelecer um primeiro diagnóstico da situação, dos problemas prioritários e de eventuais ações. Após o levantamento de todas as informações iniciais, os pesquisadores e os participantes estabelecem os principais objetivos da pesquisa. Os objetivos dizem respeito aos problemas considerados prioritários, ao campo de observação, aos atores e ao tipo de ação que serão focalizados no processo de investigação.

Nesta etapa também deve ser definido o tema da pesquisa. Thiollent (2007) afirma que o tema da pesquisa é a designação do problema (científico e prático) e da área de conhecimento a serem abordados. 0 tema deve ser definido de modo simples e sugerir os problemas e o enfoque que serão selecionados. Na pesquisa-ação, a definição do tema e seu desdobramento em problemas a serem detalhadamente pesquisados são realizados a partir de um processo de discussão com os participantes. Quando um primeiro problema se revelar inviável a curto prazo, é bom delimitá-lo melhor para viabilizar sua abordagem dentro de um prazo factível. $\mathrm{Na}$ pesquisa científica, o problema ideal pode remeter à constatação de um fato real não adequadamente explicado pelo conhecimento disponível, gerando lacunas no conhecimento específico sobre o tema. Trata-se de procurar soluções para chegar a um objetivo ou realizar uma possível transformação dentro da situação observada (THIOLLENT, 2007).

0 fechamento desta etapa se dá com a definição da equipe de pesquisadores e integrantes da unidade de análise que participarão de modo cooperativo na condução da pesquisa, coleta de dados e implementação das ações para a solução do problema de pesquisa identificado. Uma das primeiras tarefas dessa equipe é definir os critérios que serão utilizados para avaliar se as ações planejadas e implementadas tiveram sucesso após cada ciclo do processo de pesquisa. Para cada ciclo podem ser definidos critérios diferentes, qualitativos e/ou quantitativos. Porém, os critérios que irão medir se os objetivos técnicos e científicos da pesquisa foram alcançados mereceriam ser avaliados, quando possível, desde o primeiro ciclo da pesquisa.

Quadro 3. Questões relacionadas com a racionalidade da pesquisa-ação.

\begin{tabular}{|l|c|}
\hline \multicolumn{1}{|c|}{ Racionalidade para a ação } & Racionalidade para a pesquisa \\
\hline - Começa quando a pesquisa-ação se desdobra em tempo real; & Envolve o questionamento do porquê \\
- Os membros-chave da organização desenvolvem um entendimento do contexto do projeto da ação: & $\begin{array}{c}\text { desta ação ser digna de ser estudada, } \\
\text { como a pesquisa-ação pode ser } \\
\text { - Por que o projeto é necessário ou desejável? }\end{array}$ \\
- Quais são os fatores econômicos, políticos, sociais e técnicos que determinam a necessidade para a ação? & $\begin{array}{c}\text { considerada o método apropriado a ser } \\
\text { adotado e qual a contribuição esperada } \\
\text { - A análise dessas forças identifica sua fonte, sua potencialidade e a natureza da demanda que elas } \\
\text { têm sobre o sistema. }\end{array}$ \\
\hline
\end{tabular}

Fonte: Coughlan e Coghlan (2002). 


\subsection{Coletar dados}

Os dados são coletados de diferentes formas, dependendo do contexto, por grupos de observação e por pesquisadores. Existem os dados secundários. Esses dados são coletados através, por exemplo, de estatística operacional, informes financeiros e relatórios de marketing. Existem também os chamados dados primários. Esses são coletados através de observação, discussões e entrevistas. Esses dados são baseados na percepção e pode ser difícil a interpretação da sua validade (COUGHLAN; COGHLAN, 2002). A todo momento esses dados precisam ser registrados, criando-se um banco de dados da pesquisa para uso posterior nas outras fases do processo.

Coughlan e Coghlan (2002) consideram que, para o pesquisador, a obtenção dos dados acontece no envolvimento ativo no dia a dia dos processos organizacionais relacionados com o projeto de pesquisa-ação. Os dados não são obtidos apenas com a participação e observação das equipes no trabalho, dos problemas sendo resolvidos, das decisões tomadas, mas também por meio de intervenções feitas para fazer avançar o projeto de pesquisa. Algumas dessas observações e intervenções são realizadas de maneira formal, por meio de reuniões e entrevistas; muitas são realizadas de maneira informal, durante o cafezinho, jantar ou atividades recreativas.

Thiollent (2007) afirma que sejam quais forem as técnicas utilizadas, os grupos de observação compostos de pesquisadores e de participantes comuns procuram a informação que é julgada necessária para 0 andamento da pesquisa, respondendo a solicitação da etapa de monitoramento da pesquisa. Neste trabalho, esta etapa é denominada ciclo de melhoria e aprendizagem e será discutida adiante. Todas as informações coletadas e registradas pelos diversos grupos de observação e pesquisadores de campo são transferidas para este ciclo, onde são discutidas, analisadas, interpretadas etc.

0 pesquisador recolhe os dados coletados e alimenta o sistema cliente a fim de torná-los disponíveis para análise. Algumas vezes o pesquisador coleta os dados e faz o relatório; outras a própria organização coleta os dados e o pesquisador facilita ou participa das reuniões de alimentação (COUGHLAN; COGHLAN, 2002). Essas reuniões ocorrem durante o ciclo de melhoria e aprendizagem.

As formas mais comuns de coleta de dados, citadas e utilizadas por pesquisadores (KOCK; JENKINS; WELLINGTON, 1999; MIGUEL, 2009; FRENCH, 2009), incluem diário de pesquisa (com transcrição das discussões), participação em reuniões, participação em seminários (debates e registros em notas), análise documental (atas, relatórios etc.), entrevistas com informantes-chave e gravação das entrevistas (desde que autorizadas pelos respondentes).

\subsection{Analisar os dados e planejar as ações}

Segundo Coughlan e Coghlan (2002), o aspecto crítico da análise de dados na pesquisa-ação é que ela é colaborativa, tanto o pesquisador quanto os membros do sistema cliente (por exemplo, o time de gerentes, um grupo de clientes etc.) fazem-na juntos. Esta abordagem colaborativa é baseada na suposição de que os clientes conhecem melhor a sua empresa, sabem o que irá funcionar e, principalmente, serão aqueles que irão implantar e acompanhar a implementação das ações, portanto seu envolvimento na análise é crucial. Os critérios e as ferramentas de análise precisam ser discutidos e, em última instância, estar diretamente ligados ao propósito da pesquisa e ao âmago das intervenções.

Durante a análise de dados é pertinente a comparação dos dados tabulados com a teoria envolvida no tema pesquisado. Os resultados estão coerentes com o disposto na teoria? Existem dados contraditórios? Os dados são convergentes? Essas são algumas questões que o pesquisador pode se fazer para auxiliá-lo na análise dos dados. Diferentemente dos problemas do dia a dia da empresa, é recomendável que a análise dos dados relacionados ao problema de pesquisa, que aponta uma lacuna teórica ou empírica, seja coordenada pelo pesquisador, por ele conhecer melhor o método científico, cuja análise pode posteriormente compartilhar com os demais integrantes do grupo responsável pela condução da pesquisa (inclusive os colaboradores da organização pesquisada).

Como um dos objetivos da pesquisa-ação compreende a resolução um problema prático, o final da etapa de análise de dados se dá pela elaboração e documentação de um plano de ação. Este plano deve incluir todas as recomendações para a solução do problema, bem como indicar os responsáveis pela sua implantação e o prazo dela. As recomendações devem ser elaboradas e registradas de maneira conjunta pelos pesquisadores e pelos participantes da organização.

Coughlan e Coghlan (2002) consideram que o plano de ação necessita responder a algumas questões-chave: 0 que precisa mudar? Em que partes da organização? Que tipo de mudanças são necessárias? Que tipo de apoio é necessário? Como é o compromisso a ser formalizado? Qual é a resistência a ser gerenciada? Para esses autores, essas questões são críticas e necessitam ser respondidas como parte do plano de mudança. 


\subsection{Implementar o plano de ação}

Nesta etapa os participantes da pesquisa na organização implementam o plano de ação. Segundo Thiollent (2007), a ação corresponde ao que precisa ser feito (ou transformado) para realizar a solução de um determinado problema, visando ainda refinar ou estender a teoria pesquisada, uma vez que os métodos qualitativos contribuem pouco na geração de novas teorias. Para Coughlan e Coghlan (2002), os planos devem ser implantados de forma colaborativa com os membros-chave da organização.

\subsection{Avaliar resultados e gerar relatório}

Westbrook (1995) considera que na pesquisa-ação o processo de pesquisa necessita ser proativamente gerenciado. Para ele, a qualidade dos resultados pode depender tanto da gestão do projeto de pesquisa quanto do próprio projeto de pesquisa ou da análise dos resultados. Portanto, a avaliação dos resultados deve ter como base os objetivos da pesquisa (científico e técnico) e as proposições estabelecidas no início da pesquisa.

Coughlan e Coghlan (2002) consideram que a avaliação envolve uma reflexão sobre os resultados da ação, tanto intencionais quanto não intencionais, e uma revisão do processo, para que o próximo ciclo de planejamento e ação possa beneficiar-se do ciclo completado. A avaliação é a chave para o aprendizado. Sem ela as ações são implementadas ao acaso, independentemente de sucesso ou fracasso, e assim erros tendem a se proliferar, gerando um aumento da ineficácia e da frustração.

Algumas das formas de avaliação de resultados da pesquisa-ação citadas e utilizadas por diversos pesquisadores são: reuniões do pesquisador com colaboradores da empresa pesquisada (MATTOS NETO, 2005; LEONEL, 2007; NORONHA, 2009; CARVALHO, 2009), apresentações para direção e grupos interessados na pesquisa (MIGUEL, 2009); comparações com os critérios (indicadores) definidos na fase de coleta de dados, antes e depois da intervenção do pesquisador (MIGUEL, 2009; CARVALHO, 2009); e comparação entre projetos de pesquisa similares com e sem intervenção do pesquisador (CARVALHO, 2009).

Uma vez coletados todos os dados, e considerando a triangulação desses dados (várias fontes de evidência, consideradas dentro das perspectivas da teoria, do pesquisador e do objeto de estudo), o pesquisador necessita elaborar uma narrativa da pesquisa realizada. Especificamente para a pesquisa-ação, devido à sua natureza cíclica, os pesquisadores podem encontrar certa dificuldade para registrar no relatório esses desdobramentos.
Para superar tal dificuldade, assim como ocorre quando o método escolhido é o estudo de caso, na pesquisa-ação também é necessário fazer uma redução dos dados, para torná-los apresentáveis e facilitar sua análise e posterior discussão. Para tal, propõe-se a elaboração de um quadro resumo, onde cada ciclo de pesquisa-ação realizado é descrito resumidamente, informando o seu período (data) de realização, a qual fase da pesquisa corresponde (Figura 1), os critérios para avaliação adotados para cada ciclo, as atividades realizadas (com indicação dos participantes), os resultados da avaliação realizada e os aprendizados e melhorias que podem ser empregados nos próximos ciclos. 0 Quadro 4 mostra um exemplo do quadro resumo. Os trabalhos de Carvalho (2009), Noronha (2009) e Miguel (2009) apresentam exemplos do uso do quadro resumo e da condução da pesquisa em ciclos bem definidos.

Todas as etapas citadas anteriormente devem ser sintetizadas em um relatório de pesquisa, que vai auxiliar o pesquisador na elaboração de sua monografia, dissertação, tese ou artigo.

No caso de dissertações e teses, pode-se adotar a estratégia de apresentar os dados resumidamente no corpo do trabalho, apresentando a narrativa completa no apêndice, como foi feito por Serson (1996).

\subsection{Ciclo de melhoria e aprendizagem}

Este ciclo ocorre conjuntamente com praticamente todas as outras fases da proposta de condução da pesquisa-ação (Figura 1). Ele se assemelha à fase de monitoramento proposta por Coughlan e Coghlan (2002) e ao seminário proposto por Thiollent (2007). Não se trata de uma nova proposta para a condução da pesquisa-ação mas, simplesmente, de uma constatação da importância do ciclo de melhoria e aprendizagem nas diversas fases desse processo de pesquisa.

0 ciclo pode ser considerado uma adaptação do ciclo PDCA (plan-do-check-act), proposto por Deming (1997) e reforça a idéia de Lewin (1946) de que o método de pesquisa-ação desenvolve-se em ciclos de planejamento, execução e reconhecimento ou descoberta de fatos, com o propósito de avaliar os resultados e preparar uma base racional para novos planejamentos.

Ballantyne (2004) afirma que o ciclo da pesquisaação clássico envolve mudança e aprendizagem, organizadas em fases interativas de ação e reflexão. A reflexão conduz ao entendimento e o entendimento, compartilhado pelos participantes, é realimentado pela ação. Este ciclo continua até que os objetivos da pesquisa sejam atingidos ou abandonados ou, ainda, até que esses objetivos sejam revisados e o processo comece novamente. 
Quadro 4. Exemplo ilustrativo do quadro resumo para pesquisa-ação.

\begin{tabular}{|c|c|c|c|c|c|c|}
\hline Ciclo & Período & $\begin{array}{l}\text { Fase da } \\
\text { pesquisa }\end{array}$ & $\begin{array}{l}\text { Critérios de } \\
\text { avaliação }\end{array}$ & Atividades executadas & Avaliação & Melhoria e aprendizagem \\
\hline 1 & $\begin{array}{c}\text { Julho a Agosto } \\
\text { de } 2008\end{array}$ & $\begin{array}{l}\text { Definir } \\
\text { estrutura } \\
\text { conceitual } \\
\text { teórica }\end{array}$ & $\begin{array}{l}\text { Definição e } \\
\text { codificação } \\
\text { das variáveis } \\
\text { de estudo no } \\
\text { sistema. }\end{array}$ & $\begin{array}{l}\text { Revisão de literatura; } \\
\text { coleta de pequena } \\
\text { amostra de clientes } \\
\text { para análise inicial dos } \\
\text { dados. }\end{array}$ & $\begin{array}{l}\text { Existência de muitos campos } \\
\text { vazios. A variável X se } \\
\text { mostrou de difícil utilização. } \\
\text { Os clientes com mais de } 18 \\
\text { meses de inatividade foram } \\
\text { eliminados. }\end{array}$ & $\begin{array}{l}\text { Verificar a necessidade de } \\
\text { eliminar campos; definir novas } \\
\text { respostas para alguns campos } \\
\text { do sistema; aprofundar revisão } \\
\text { de literatura. }\end{array}$ \\
\hline$\ldots$ & $\ldots$ & $\ldots$ & $\ldots$ & $\ldots$ & $\ldots$ & $\ldots$ \\
\hline 7 & $\begin{array}{l}\text { Abril a Maio } \\
\text { de } 2009\end{array}$ & $\begin{array}{c}\text { Analisar } \\
\text { dados. }\end{array}$ & $\begin{array}{l}\text { Correlação } \\
\text { das variáveis } \\
\text { com divisão de } \\
\text { grupos. }\end{array}$ & $\begin{array}{l}\text { A amostra para função } \\
\text { discriminante foi } \\
\text { dividida para cada um } \\
\text { dos três grupos. Foi } \\
\text { testada pela primeira } \\
\text { vez a categorização } \\
\text { manual das variáveis. }\end{array}$ & $\begin{array}{c}\text { A variável } \mathrm{Z} \text { já estava } \\
\text { categorizada em três grupos, } \\
\text { e os campos } \mathrm{X} \text { e } \mathrm{Y} \text { foram } \\
\text { removidos, dando lugar ao } \\
\text { novo campo } \mathrm{W} \text {. }\end{array}$ & $\begin{array}{l}\text { Retornar a divisão dos grupos } \\
\text { utilizando } 30 \text { e } 60 \text { dias; em } \\
\text { reunião com os profissionais } \\
\text { da empresa, decidiu-se dar } \\
\text { uma tolerância para clientes } \\
\text { que tivessem } 20 \text { ou mais } \\
\text { duplicatas pagas. }\end{array}$ \\
\hline$\ldots$ & $\ldots$ & $\ldots$ & $\ldots$ & $\ldots$ & $\ldots$ & $\ldots$ \\
\hline
\end{tabular}

0 ciclo de melhoria e aprendizagem (Figura 1) é composto de quatro etapas, planejar (P), implementar (1), observar e avaliar (O\&A) e refletir e agir (R\&A).

A fase de planejamento contempla o momento em que a equipe formada por pesquisadores e participantes da empresa se reúne para analisar o problema, propor possíveis ações, definir responsabilidades e prazos. Em cada fase, o problema pode ser diferente. $\mathrm{Na}$ etapa de definição da estrutura conceitual-teórica, o problema pode ser mapear a literatura. Já na etapa de planejamento da pesquisa-ação, ele pode ser a seleção das técnicas de coleta de dados que melhor se adaptem à pesquisa em questão.

A fase de implementação consiste na colocação em prática das ações planejadas na fase anterior. Muitas vezes, essa implementação será conduzida pelos participantes da empresa, a não ser que ao pesquisador tenha sido dada esta autorização por parte da alta direção da empresa estudada.

A fase de observação e avaliação consiste na verificação das ações implementadas e do impacto dessas para a solução do problema em pauta. Nessa fase, o pesquisador emprega a observação participante para intervir no objeto de pesquisa e avaliar o sucesso ou insucesso das suas intervenções e das ações planejadas e implementadas.

Na fase de reflexão e ação, o pesquisador reflete sobre as ações implementadas e suas intervenções. Com base nesta reflexão, ele toma ou recomenda ações para atender aos propósitos originais da pesquisa, em termos científicos e práticos. Essas ações podem desencadear novos planos ou alterações em planos já estabelecidos, fazendo com que o processo de pesquisa ocorra em ciclos contínuos, como previsto por Lewin (1946).
Portanto, o ciclo de melhoria e aprendizagem é operacionalizado através de reuniões entre os pesquisadores e os participantes da organização. Nele se centralizam todas as informações coletadas e se discutem as interpretações, sendo que seus resultados devem ser registrados para garantir o aprendizado.

\subsection{Validade e confiabilidade $d a$ pesquisa-ação}

A pesquisa-ação, assim como qualquer outro método de pesquisa científica, deve ser pautada na confiabilidade e validade, características que mensuram sua qualidade ou rigor científico. Yin (2005) define confiabilidade como a capacidade de demonstrar que os procedimentos de uma pesquisa (por exemplo, as etapas de coleta ou análise de dados) podem ser repetidos apresentando os mesmos resultados. Como o método da pesquisa-ação é geralmente considerado uma variação do método de estudo de caso (WESTBROOK, 1995), considera-se que as definições de Yin (2005) para confiabilidade e validade sejam adequadas também para a pesquisaação. Schwab (2005) considera que uma pesquisa é válida quando suas conclusões ou inferências são verdadeiras. Yin (2005) classifica a validade em interna, externa e de construto. Thompson e Perry (2004) citam ainda a validade contingente, que demonstra que um relatório científico denomina e descreve alguns mecanismos generativos gerais que explicam como os construtos podem operar em seu contexto. Neste tipo de validade, a pesquisa emprega diversas abordagens para assegurar que as incertas fronteiras dos sistemas sociais envolvidos e a natureza contemplativa dos atores participantes desses sistemas foram consideradas no projeto de pesquisa. 
Lembrando que a qualidade de uma pesquisa científica só pode ser julgada nos termos específicos do paradigma no qual o pesquisador está trabalhando (HEALY; PERRY, 2000), ou seja, que os critérios adotados em um paradigma podem ser quase insignificantes em outro, Thompson e Perry (2004) sugerem seis critérios para avaliar a qualidade (validade e confiabilidade) da pesquisa-ação sob o paradigma do realismo: adequação ontológica, validade contingente, percepções múltiplas de participantes e pesquisadores associados, fidedignidade metodológica, generalização analítica e validade de construto. 0 Quadro 5 apresenta detalhes de como esses seis critérios podem ser empregados.

0 Quadro 5 apresenta alguns aspectos iniciais para a validação do processo de pesquisa-ação. 0 paradigma adotado, designado por Healy e Perry (2000) como realismo, propõe esses seis critérios para a análise da validade do processo científico.

Em um primeiro instante, pode-se questionar os critérios propostos, entretanto este não é o objetivo deste trabalho. Assim, considerando que os critérios propostos por Thompson e Perry (2004) são válidos, pode-se discutir como conduzir a avaliação de cada uma das etapas da pesquisa-ação.

A adequação ontológica é obtida na fase preparatória do processo, na qual se busca demonstrar que ele foi conduzido segundo as etapas previstas, como ilustrado pela Figura 1.

A validade contingente trata da contextualização do processo. Nela, o pesquisador demonstra que o processo de pesquisa foi planejado visando chegar a uma contribuição científica e não como uma simples aplicação de determinada tecnologia para a solução de problemas, como acontece no caso de projetos de consultoria. A diferenciação acontece na etapa de coleta de dados, na qual o pesquisador deve preocupar-se com a identificação de evidências que permitam a análise do fenômeno e a sua comparação com a teoria já estabelecida.

$\mathrm{Na}$ etapa de coleta de dados também são validados os instrumentos de obtenção dos dados, nela se destaca o uso de fontes múltiplas, que permitem a triangulação dos dados e o confronto das interpretações do pesquisador com as evidências documentais e a percepção dos pesquisados.

Quadro 5. Critérios para avaliação da qualidade da pesquisa-ação.

\begin{tabular}{|c|c|c|c|}
\hline Critério & Objetivo do critério e medidas aplicadas & $\begin{array}{c}\text { Fase da pesquisa } \\
\text { utilizada }\end{array}$ & Medidas aplicadas na pesquisa \\
\hline $\begin{array}{l}\text { 1. Adequação } \\
\text { ontológica }\end{array}$ & $\begin{array}{l}\text { O problema de pesquisa lida com o } \\
\text { complexo fenômeno das ciências sociais } \\
\text { envolvendo pessoas conscientes. Demonstra } \\
\text { que o mundo que está sendo investigado é } \\
\text { criação independente de mentes e criaturas } \\
\text { vivas ou do mundo de ideias, arte, ciências, } \\
\text { linguagens, ética e instituições. }\end{array}$ & $\begin{array}{l}\text { Projeto da } \\
\text { pesquisa e análise } \\
\text { de dados. }\end{array}$ & $\begin{array}{l}\text { Formulação adequada da questão de pesquisa; } \\
\text { uso da teoria prévia; fundamentação teórica; } \\
\text { projeto da pesquisa-ação; triangulação de dados; } \\
\text { desenvolvimento da base de dados da pesquisa } \\
\text { e de evidências para avaliação. }\end{array}$ \\
\hline $\begin{array}{l}\text { 2. Validade } \\
\text { contingente }\end{array}$ & $\begin{array}{l}\text { Estabelece a validade sobre mecanismos } \\
\text { generativos que são denominados e } \\
\text { descobertos pela pesquisa e os contextos } \\
\text { que os tornam contingentes (eventuais). }\end{array}$ & $\begin{array}{l}\text { Projeto da } \\
\text { pesquisa e análise } \\
\text { de dados. }\end{array}$ & $\begin{array}{c}\text { Projeto da pesquisa-ação; detalhes das circunstâncias } \\
\text { organizacionais e do principal contexto do projeto da } \\
\text { pesquisa-ação; desenvolvimento da base de dados da } \\
\text { pesquisa e de evidências para avaliação. }\end{array}$ \\
\hline $\begin{array}{l}\text { 3. Percepções } \\
\text { múltiplas de } \\
\text { participantes e } \\
\text { pesquisadores } \\
\text { associados }\end{array}$ & $\begin{array}{l}\text { Demonstra como a pesquisa revela o } \\
\text { mundo real, embora de uma forma que seja } \\
\text { apenas imperfeita e probabilisticamente } \\
\text { compreensível. } 0 \text { foco está na sensibilização } \\
\text { dos valores da pesquisa. }\end{array}$ & $\begin{array}{l}\text { Projeto da } \\
\text { pesquisa, coleta e } \\
\text { análise de dados, } \\
\text { posterior análise } \\
\text { de dados. }\end{array}$ & $\begin{array}{l}\text { Fontes de dados múltiplas; apresentação de evidências } \\
\text { de apoio; questionamento amplo em entrevistas antes } \\
\text { das questões exploratórias; triangulação de dados; } \\
\text { consciência dos valores próprios e seu impacto na } \\
\text { coleta de dados; revisão por pares. }\end{array}$ \\
\hline $\begin{array}{l}\text { 4. Fidedignidade } \\
\text { metodológica }\end{array}$ & $\begin{array}{l}\text { Estabelecimento de um relatório que } \\
\text { possa ser avaliado. }\end{array}$ & $\begin{array}{l}\text { Projeto de } \\
\text { pesquisa, coleta e } \\
\text { análise de dados. }\end{array}$ & $\begin{array}{l}\text { Desenvolvimento da base de dados da pesquisa e de } \\
\text { evidências para avaliação; uso frequente de citações } \\
\text { relevantes no relatório para fundamentar a construção } \\
\text { da teoria; descrições de procedimentos com detalhes } \\
\text { de datas, respondentes e tempo. }\end{array}$ \\
\hline $\begin{array}{l}\text { 5. Generalização } \\
\text { analítica }\end{array}$ & $\begin{array}{l}\text { Estabelecimento da primazia da construção } \\
\text { da teoria no relatório. }\end{array}$ & $\begin{array}{l}\text { Projeto de } \\
\text { pesquisa, coleta e } \\
\text { análise de dados. }\end{array}$ & $\begin{array}{l}\text { ldentificação das questões de pesquisa antes da } \\
\text { coleta de dados; desenvolvimento da teoria por meio } \\
\text { da triangulação de dados; não utilização de } \\
\text { técnicas quantitativas. }\end{array}$ \\
\hline $\begin{array}{l}\text { 6. Validade de } \\
\text { construto }\end{array}$ & $\begin{array}{c}\text { Determina quão bem os construtos na teoria } \\
\text { que está sendo construída são mensuráveis } \\
\text { pela pesquisa. }\end{array}$ & $\begin{array}{l}\text { Projeto de } \\
\text { pesquisa, coleta e } \\
\text { análise de dados. }\end{array}$ & $\begin{array}{l}\text { Fundamentação teórica; entrevistas com especialistas } \\
\text { de diferentes áreas; desenvolvimento e uso de } \\
\text { protocolos de entrevistas; avaliação de publicações } \\
\text { e documentos de origem interna das empresas; } \\
\text { desenvolvimento de uma base de dados detalhando } \\
\text { o encadeamento de evidências; devolutivas das } \\
\text { transcrições das entrevistas aos informantes para } \\
\text { confirmação e comentários; revisão das versões } \\
\text { rascunho do relatório pelos pares. }\end{array}$ \\
\hline
\end{tabular}


A fidedignidade metodológica garante que o trabalho apresenta dados confiáveis. 0 relato necessita ser detalhado e estar o mais próximo possível do que foi planejado na etapa 1 (planejar a pesquisaação). Isso demostra o cuidado do pesquisador com a cientificidade do processo de pesquisa, de forma a permitir generalização analítica.

A generalização analítica é etapa do processo de validação proposto no qual, no relatório obtido, são apresentados os resultados, que confirmam ou refutam a teoria, e as condições em que os mesmos foram obtidos, permitindo assim que outros pesquisadores continuem a explorar o tema.

0 último critério proposto, validade do construto, busca a avaliação dos resultados. 0 pesquisador deve se valer, então, do encadeamento de evidências obtido e da discussão dos resultados com seus pares para caracterizar as contribuições do processo de pesquisa-ação e identificar os problemas de pesquisa ainda não abordados.

\section{Conclusões}

Pretende-se que o presente trabalho seja discutido por pesquisadores brasileiros que empregam a pesquisaação, para que possa ser complementado, uma vez que ele não cobriu absolutamente todos os aspectos desse método de pesquisa e nem tem a pretensão de ser a última palavra sobre ele. A comunidade científica da engenharia de produção necessita se aprofundar cada vez mais sobre os métodos de pesquisa, uma vez que cada vez mais isso se torna uma exigência para a produção e publicação de trabalhos em veículos nacionais e internacionais.

Considera-se que o presente trabalho atingiu seus objetivos. Foi proposto e discutido um processo para a condução da pesquisa-ação na engenharia de produção, apresentando-se técnicas e ferramentas empregadas pelos pesquisadores para operacionalizar o processo. Foi dada atenção aos tipos de processos de iniciação da pesquisa-ação (motivada pelo pesquisador ou pelo problema), os quais não haviam sido tratados em outros trabalhos sobre o assunto no Brasil. Além disso, o presente trabalho discutiu uma série de critérios para a validação dos trabalhos de pesquisa-ação, dentro do paradigma do realismo, propondo a melhor forma de implementação dos mesmos. Considera-se, portanto, a discussão sobre as formas de iniciação e dos critérios de validação para a pesquisa-ação como as maiores contribuições deste trabalho para a base de conhecimento.

A utilização da pesquisa-ação precisa ser melhor explorada. A sua não aceitação como processo científico, assim como de outros métodos qualitativos, pode decorrenter disso.
A discussão dos critérios passíveis de serem utilizados no processo de validação da pesquisa-ação pode ser um caminho na direção da consolidação deste método como processo científico.

Desta forma, sugere-se explorar em trabalhos futuros o uso desses critérios nos processos de pesquisa que utilizem a pesquisa-ação dentro da engenharia de produção. Outra sugestão seria abordar a definição de construtos e a elaboração de protocolos de pesquisa específicos ao âmbito da pesquisa-ação. Espera-se, assim, que o presente trabalho contribua para a consolidação das pesquisas em engenharia de produção no Brasil.

\section{Referências}

AVISON, D.; BASKERVILLE, R.; MYERS, M. Controlling action research projects. Information Technology \& People, v. 14, n. 1, p. 28-45, 2001. http://dx.doi. org/10.1108/09593840110384762

BALLANTYNE,D.Action research reviewed:a market-orientedapproach. European Journal of Marketing, v. 38, n. 3-4, p. 321-337, 2004. http://dx.doi.org/10.1108/03090560410518576

BASKERVILLE, R.;PRIES-HEJE, J.Grounded action research: a method for understanding IT in practice. Accounting, Management and Information Technology, v. 9, n. 1, p. 1-23, 1999. http://dx.doi. org/10.1016/S0959-8022(98)00017-4

BERTO, R. M. V. S.; NAKANO, D. N. A produção científica nos anais do Encontro Nacional de Engenharia de Produção: um levantamento de métodos e tipos de pesquisa. Produção, v. 9, n. 2, p. 65-76, 2000. http://dx.doi.org/10.1590/S010365131999000200005

BRYMAN, A. Research methods and organization studies (contemporary social research). 1st ed. London: Routledge, 1989. http://dx.doi.org/10.4324/9780203359648

CARR, W. Philosophy, methodology and action research. Journal of Philosophy of Education, v. 40, n. 4, p. 421-435, 2006. http://dx.doi.org/10.1111/j.1467-9752.2006.00517.x

CARVALHO, B. V. Aplicação do método ágil Scrum no desenvolvimento de produtos de software em uma pequena empresa de base tecnológica. 2009. 100 f. Dissertação (Mestrado em Engenharia de Produção)-Universidade Federal de ltajubá, Itajubá, 2009.

CHECKLAND, P.; HOLWELL, S. Action research: its nature and validity. Systemic Practice and Action Research, v. 11, n. 1, p. 9-21, 1998. http://dx.doi.org/10.1023/A:1022908820784

CHIMENDES, V. C. G. Análise de modelo para projeto e desenvolvimento de serviços: pesquisa-ação em empresa de transporte rodoviário de passageiros. 2007. 218 f. Dissertação (Mestrado em Engenharia de Produção)-Universidade Federal de ltajubá, ltajubá, 2007.

COGHLAN, D.; BRANNICK, T. Doing action research in your own organization. 2nd ed. London: Sage, 2008.

COUGHLAN, P.; COGHLAN, D. Action research for operations management. International Journal of Operations \& Production Management, v. 22, n. 2, p. 220-240, 2002. http://dx.doi.org/10.1108/01443570210417515

CRAIGHEAD, C. W.; MEREDITH, J. Operations management research: evolution and alternative future paths. International Journal of Operations \& Production Management, v. 28, n. 8, p. 710-726,2008.http://dx.doi.org/10.1108/01443570810888625

CRESWELL, J. W. Projeto de pesquisa: métodos qualitativo, quantitativo e misto. Trad. Luciana de Oliveira Rocha. 2. ed. Porto Alegre: Artmed, 2007.

DEMING, W. E. A nova economia para a indústria, o governo e a educação. São Paulo: Qualitymark, 1997. 
DESHPANDE, R. Paradigms lost: on theory and method in research in marketing. Journal of Marketing, v. 47, Fall, p. 101-110, 1983. http://dx.doi.org/10.2307/1251403

FILIPPINI, R. Operations management research: some reflections on evolution, models and empirical studies in 0M. International Journal of Operations \& Production Management, v. 17, n. 7, p. 655-670, 1997. http://dx.doi. org/10.1108/01443579710175583

FRENCH, S. Action research for practicing managers. Journal of Management Development, v. 28, n. 3, p. 187-204, 2009.

GUBA, E.; LINCOLN, Y. Competing paradigms in qualitative research. In: Dezin, N. K.; Lincoln, Y. (Eds.). Handbook of qualitative research. Newbury Park: Sage, 1994.

HEALY, M.; PERRY, C. Comprehensive criteria to judge validity and reliability of qualitative research within the realism paradigm. Qualitative Market Research: an International Journal, v. 3, n. 3, p. 118-126, 2000. http://dx.doi. org/10.1108/13522750010333861

KOCK, N; JENKINS, A.; WELLINGTON, R. A field study of success and failure factors in asynchronous groupware supported process improvement groups. Business Process Management Journal, v. 5, n. 3, p. 238-253, 1999. http://dx.doi. org/10.1108/14637159910283010

LEONEL, S. G. Um estudo do processo de planejamento tecnológico de uma empresa nascente: alinhando tecnologia, produto e mercado com foco na necessidade do cliente. 2007. $150 \mathrm{f}$. Dissertação (Mestrado em Engenharia de Produção)Universidade Federal de Minas Gerais, Belo Horizonte, 2007.

LEWIN, K. Action research and minority problems. Journal of Social Issues, v. 2, p. 34-46, 1946. http://dx.doi. org/10.1111/j.1540-4560.1946.tb02295.x

MARCONI, M. A.; LAKATOS, E. V. Fundamentos de metodologia científica. 6. ed. São Paulo: Editora Atlas, 2006.

MATTOS NETO, P. Planejamento de novos produtos por intermédio do Método Technology Roadmapping (TRM) em uma pequena empresa de base tecnológica do setor de internet móvel. 2005. 141 f. Dissertação (Mestrado em Engenharia de Produção)-Universidade Federal de Minas Gerais, Belo Horizonte, 2005.

MCINNES, P.; HIBBERT, P.; BEECH, N. Exploring the complexities of validity claims in action research. Management Research News, v. 30, n. 5, p. 381-390, 2007. http://dx.doi. org/10.1108/01409170710746373

MIGUEL, P. A. C. QFD no desenvolvimento de novos produtos: um estudo sobre a sua introdução em uma empresa adotando a pesquisa-ação como abordagem metodológica. Produção, v. 19, n. 1, p. 105-128, 2009. http://dx.doi.org/10.1590/ S0103-65132009000100008

NORONHA, J. C. Opcões reais aplicadas à gestão do processo de desenvolvimento de produto em uma indústria de autopeças. 2009. 137 f. Dissertação (Mestrado em Engenharia de Produção)-Universidade Federal de Itajubá, Itajubá, 2009.
OQUIST, P. The epistemology of action research. Acta Sociologica, v. 21, n. 2, p. 143-163, 1978. http://dx.doi. org/10.1177/000169937802100204

RIORDAN, P. The philosophy of action science. Journal of Managerial Psychology, v. 10, n. 6, p. 6-13, 1995. http:// dx.doi.org/10.1108/02683949510093821

ROWLEY, J.; SLACK, F. Conducting a literature review. Management Research News, v. 27, n. 6, p. 31-39, 2004 http://dx.doi.org/10.1108/01409170410784185

SCHWAB, D. P. Research methods for organizational studies. 2. ed. London: Routledge, 2005.

SERSON, S. M. Fábrica veloz: um modelo para competir com base no tempo. 1996. 159 f. Dissertação (Mestrado em Engenharia de Produção)-Universidade de São Paulo, 1996.

SUSMAN, G. 1.; EVERED, R. D. An assessment of the scientific merits of action research. Administrative Science Quarterly, v. 23, p. 582-603, 1978. http://dx.doi.org/10.2307/2392581

THIOLLENT, M. Metodologia da pesquisa-ação. 15. ed. São Paulo: Cortez, 2007.

THOMPSON, F.; PERRY, C. Generalizing results of an action research project in one work place to other situations: principals and practice. European Journal of Marketing, v. 38, n. 3-4, p. 401-417, 2004. http://dx.doi. org/10.1108/03090560410518611

TORRACO, R. J. Writing integrative literature reviews: guidelines and examples. Human Resource Development Review, v. 4, n. 3, p. 356-367, 2005. http://dx.doi. org $/ 10.1177 / 1534484305278283$

WESTBROOK, R. Action research: a new paradigm for research in production and operations management. International Journal of Operations \& Production Management, v. 15, n. 12, p. 6-20, 1995. http://dx.doi. org/10.1108/01443579510104466

WINTER, R. Truth or fiction: problems of validity and authenticity in narratives of action research. Educational Action Research, v. 10, n. 1, p. 143-154, 2002. http://dx.doi. org/10.1080/09650790200200178

WOODSIDE, A. G.; WILSON, E. J. Case studies research methods for theory building. Journal of Business and Industrial Marketing, v. 18, n. 6/7, p. 493-508, 2003. http://dx.doi. org/10.1108/08858620310492374

YIN, R. Estudo de caso: planejamento e métodos. 3. ed. Porto Alegre: Bookman, 2005.

\section{Agradecimentos}

Os autores agradecem à FAPEMIG, ao CNPq e à Capes pelo apoio e fomento à pesquisa e, especialmente para este trabalho, pelas bolsas de mestrado concedidas.

\title{
Action research in production engineering: a structure proposal for its conduction
}

\begin{abstract}
Action research is a qualitative method that is increasingly achieving a place of prominence as a technical procedure used in production engineering research. However, this method is discriminated in its scientific merit and lacks conduction validation. In an attempt to fill in these gaps in the literature, this paper proposes a process for conducting research in production engineering by means of action research. The scientific contributions of this work are the discussion about the forms of initiation and the implementation of validation phases employing the action research method. It was concluded that, within the scientific paradigm of realism, the most appropriate criteria for the validation of action research method are the ontological appropriateness, contingent validity, multiple perception of participants, methodological trustworthiness, analytic generalization, and construction validity.
\end{abstract}

Keywords

Production engineering. Action research. Research methodology. 